\title{
AEROSOL BACKSCATTER AND EXTINCTION RETRIEVAL FROM AIRBORNE COHERENT DOPPLER WIND LIDAR MEASUREMENTS
}

\author{
F. Chouza ${ }^{1}$, O. Reitebuch ${ }^{1}$, S. Groß ${ }^{1}$, S. Rahm ${ }^{1}$, V. Freudenthaler ${ }^{2}$, C. Toledano ${ }^{3}$, B. Weinzierl ${ }^{1,2}$ \\ ${ }^{1}$ Institut für Physik der Atmosphäre, Deutsches Zentrum für Luft- und Raumfahrt (DLR), \\ Oberpfaffenhofen, Germany, *Email: fernando.chouza@dlr.de \\ ${ }^{2}$ Meteorologisches Institut, Ludwig-Maximilians-Universität München (LMU), München, Germany \\ ${ }^{3}$ Atmospheric Optics Group, University of Valladolid, Valladolid, Spain
}

\begin{abstract}
A novel method for coherent Doppler wind lidars (DWLs) calibration is shown in this work. Concurrent measurements of a ground based aerosol lidar operating at $532 \mathrm{~nm}$ and an airborne DWL at $2 \mu \mathrm{m}$ are used in combination with sun photometer measurements for the retrieval of backscatter and extinction profiles.

The presented method was successfully applied to the measurements obtained during the Saharan Aerosol Long-range Transport and AerosolCloud-Interaction Experiment (SALTRACE: http://www.pa.op.dlr.de/saltrace), which aimed to characterize the Saharan dust long range transport between Africa and the Caribbean.
\end{abstract}

\section{INTRODUCTION}

Aerosol lidars allow detailed measurements of aerosol properties, whereas wind lidars provide information on horizontal and vertical transport of aerosol layers. However, in many cases it is scientifically interesting to have aerosol and wind information synchronous from one system.

Due to the strong wavelength dependence of the atmospheric molecular backscatter and the low sensitivity of the coherent detection to spectrally broad signals, calibration methods for aerosol lidars cannot be applied to a coherent DWLs usually operating at wavelengths between $1.5 \mu \mathrm{m}$ and $2 \mu \mathrm{m}$.

Up to now, different approaches where applied to retrieve calibrated backscatter coefficient from lidars to which calibration methods based on molecular return cannot be applied, including the use of ground based hard targets (Menzies and Tratt, 1994), ground return (Cutten et al., 2002), sea return (Bufton et al., 1983) and clouds (O’Connor et al., 2003).
While the main problems associated with the use of ground based hard targets are the boundary layer variability and the changes in heterodyne efficiency due to high path integrated turbulence, the sea and ground surface have either highly variable optical properties or they are limited to some specific regions (e.g. deserts).

On the other hand, the method based on cloud extinction requires presence of well characterized stratocumulus clouds.

In order to avoid the previous described problems, concurrent measurements of an airborne DWL and the ground based aerosol lidar POLIS are used in combination with sun photometer measurements to provide calibrated backscatter and extinction profiles (Chouza et al., 2005).

The proposed method was applied to the dataset obtained during the SALTRACE campaign conducted during June/July 2013, which was intended to provide a better understanding of the Saharan dust long range transport and its associated processes.

\section{INTRUMENTAL DESCRIPTION}

The coherent DWL deployed on the DLR Falcon 20 research aircraft during SALTRACE is based on a CLR Photonics instrument (Henderson et al., 1993) combined with a two wedge scanner and acquisition system developed at DLR (Köpp et al., 2004; Reitebuch, 2012). The system operates at a wavelength of $2.02254 \mu \mathrm{m}$, with a pulse full width at half maximum (FWHM) of $400 \mathrm{~ns}$, a pulse energy of 1-2 $\mathrm{mJ}$, and a repetition frequency of $500 \mathrm{~Hz}$.

\section{INSTRUMENTAL CORRECTIONS}

The backscattered power $\langle P(R)\rangle$, for a given lidar line of sight $\overrightarrow{\mathrm{L}}$ and a range gate at distance $\mathrm{R}$, can be written as: 


$$
\langle\mathrm{P}(\mathrm{R})\rangle=\frac{\mathrm{E}_{\mathrm{T}}}{\mathrm{R}^{2}} \mathrm{k}_{\mathrm{d}} \mathrm{k}_{\mathrm{in}, \overrightarrow{\mathrm{L}}}(\mathrm{R}) \mathrm{k}_{\delta}(\mathrm{R}) \beta(\mathrm{R}) \mathrm{T}^{2}(\mathrm{R})
$$

where $E_{T}$ is the mean transmitted energy of the averaged laser pulses, $R^{2}$ is the squared distance of the range gate to the lidar, $\beta$ is the backscatter coefficient, $\mathrm{T}$ the atmospheric transmission, $\mathrm{k}_{\mathrm{in}, \overrightarrow{\mathrm{L}}}(\mathrm{R})$ groups instrumental coefficients that change with the range gate range $\mathrm{R}$ and the line of sight vector $\vec{L}$ (e.g. system gain as a function of the backscattered signal frequency, transmission of the transceiver optics), $\mathrm{k}_{\delta}(\mathrm{R})$ is the detector response depending on the depolarization of the backscattered signal and $\mathrm{k}_{\mathrm{d}}$ groups other instrumental constants (e.g. telescope area).

The transmitted energy $E_{T}$ was estimated based on the pulse build up time and laboratory measurements that relates this quantity with the laser pulse energy. On the other hand, most of the different instrumental coefficients grouped in $\mathrm{k}_{\mathrm{in}, \overrightarrow{\mathrm{L}}}(\mathrm{R})$ were estimated based on atmospheric measurements for which the other instrumental and atmospheric parameters were considered to be constant.

Finally, the received backscatter power $\langle\mathrm{P}(\mathrm{R})\rangle$ is divided by the estimated instrumental constants in order to remove their effects

$$
\left\langle\mathrm{P}_{\mathrm{c}}(\mathrm{R})\right\rangle=\frac{\langle\mathrm{P}(\mathrm{R})\rangle \mathrm{R}^{2}}{\mathrm{E}_{\mathrm{T}} \mathrm{k}_{\mathrm{in}, \overrightarrow{\mathrm{L}}}(\mathrm{R})}=\mathrm{k}_{\mathrm{d}} \mathrm{k}_{\delta}(\mathrm{R}) \beta(\mathrm{R}) \mathrm{T}^{2}(\mathrm{R})
$$

\section{CALIBRATION AND RETREIVAL METHOD}

The proposed calibration method relies on concurrent measurements of the airborne DWL and a ground based aerosol lidar (in our case the POLIS system based on the island of Barbados, Caribbean) (Freudenthaler et al., 2009) from which backscatter $\beta_{532}^{\text {POLIS }}$, extinction $\alpha_{532}^{\text {POLIS }}$ and lidar ratio $S_{532}^{\text {POLIS }}\left(L_{n}\right)$ can be retrieved.

Since the DWL operates at a wavelength of $2 \mu \mathrm{m}$ and the POLIS lidar operates at $532 \mathrm{~nm}$, additional sun photometer measurements relating the extinction coefficient at both wavelengths $\mathrm{k}_{\alpha}$ are needed (Toledano et al., 2011). This relation, as well as the atmospheric depolarization, depends on the aerosol type and its vertical structure. Each layer $L_{n}$ of the atmospheric model represents an aerosol type and is defined as a region in which the particle depolarization ratio, the lidar ratio and the wavelength dependency of the extinction coefficient are considered to be constant.

During the DWL overflight over the ground based lidar POLIS (Fig. 1), the same atmospheric volume is sensed by both lidar systems. For a given range gate $\mathrm{R}$, the measured backscatter power by the DWL and the ground based lidar can be related trough the following equation

$$
\left\langle\mathrm{P}_{\mathrm{c}}(\mathrm{R})\right\rangle
$$$$
=\mathrm{k}_{\mathrm{d}} \mathrm{k}_{\delta}\left(\mathrm{L}_{\mathrm{n}}\right) \mathrm{k}_{\beta}\left(\mathrm{L}_{\mathrm{n}}\right) \beta_{532}^{\mathrm{POLIS}}(\mathrm{R}) \mathrm{e}^{-2 \int_{0}^{\mathrm{R}} \alpha_{532}^{\text {POLIS }}(\mathrm{r}) \mathrm{k}_{\alpha}\left(\mathrm{L}_{\mathrm{n}}\right) \mathrm{dr}}
$$

Grouping al parameter that remain constant for a given $L_{n}$ in a single constant $k\left(L_{n}\right)$

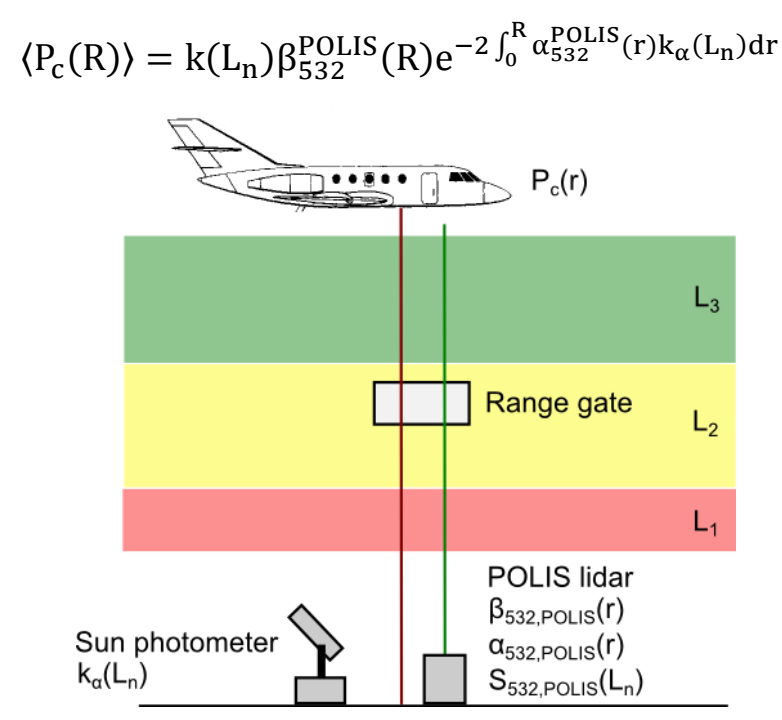

Fig. 1. Scheme of the instruments and variables involved in the calibration and retrieval process.

Finally, based on the measured extinction coefficient retrieved from POLIS and the wavelength dependency of the extinction coefficient retrieved from sun photometer measurements, a linear relation between the measured backscatter power by the DWL and the backscatter coefficient retrieved by POLIS can be established

$\frac{\left\langle\mathrm{P}_{\mathrm{c}}(\mathrm{R})\right\rangle}{\mathrm{T}_{2022, \text { POLIS }}^{2}(\mathrm{R})}=\mathrm{k}\left(\mathrm{L}_{\mathrm{n}}\right) \beta_{532}^{\text {POLIS }}(\mathrm{R})$

With

$\mathrm{T}_{2022, \text { POLIS }}^{2}(\mathrm{R})=\mathrm{e}^{-2 \int_{0}^{\mathrm{R}} \alpha_{532}^{\text {POLIS }}(\mathrm{r}) \mathrm{k}_{\alpha}\left(\mathrm{L}_{\mathrm{n}}\right) \mathrm{dr}}$

Finally, the conversion constant $k\left(L_{n}\right)$ corresponding to each layer can be estimated 
applying a LSF (Least Squares Fit) between the backscatter coefficients $\beta_{532}^{\text {POLIS }}$ measured by the ground-based lidar POLIS and the extinction corrected power measured by the DWL.

Based on the layer distribution and the conversion constants $\mathrm{k}\left(\mathrm{L}_{\mathrm{n}}\right)$ calculated for each layer, it is possible to retrieve the backscatter coefficient at $532 \mathrm{~nm}$ based on the $2 \mu \mathrm{m}$ measurements $\beta_{532}^{\mathrm{DWL}}$ through an iterative process.

$\beta_{532, \mathrm{i}}^{\mathrm{DWL}}(\mathrm{R})=\frac{\left\langle\mathrm{P}_{\mathrm{c}}(\mathrm{R})\right\rangle}{\mathrm{T}_{2022, \mathrm{i}-1}^{2}(\mathrm{R})} \frac{1}{\mathrm{k}\left(\mathrm{L}_{\mathrm{n}}\right)}$
$\alpha_{532, \mathrm{i}}^{\mathrm{DWL}}(\mathrm{R})=\beta_{532, \mathrm{i}}^{\mathrm{DWL}}(\mathrm{R}) \mathrm{S}_{532}^{\text {POLIS }}\left(\mathrm{L}_{\mathrm{n}}\right)$

with the iteration number $\mathrm{i}$ and $\mathrm{T}_{2022,0}^{2}(\mathrm{R})=1$ as starting value.

\section{RESULTS}

Figure 2 shows the linear relation between the extinction corrected backscattered power measured by the airborne DWL and the backscatter coefficient retrieved by the ground based aerosol lidar for three different aerosol types based on six overflights from the flight on 26 June 2013 over Barbados.

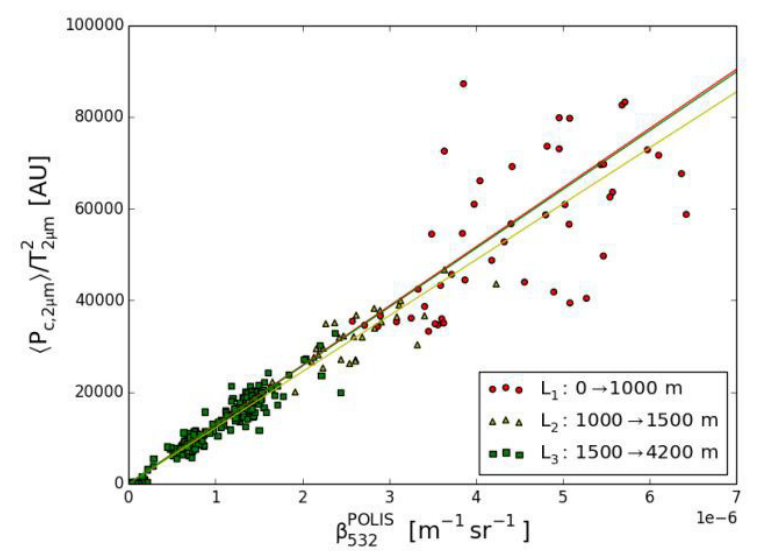

Figure 2. Correlation between the extinction corrected backscattered power of the DWL and the POLIS measured backscatter coefficient for 3 different aerosol layers: boundary layer (red dots), mixed layer (yellow triangles) and SAL (Saharan air layer) (green squares).

The retrieved calibration constants obtained from the LSF and wavelength dependency of the extinction coefficient retrieved from sun photometer measurements are presented in the following table

\begin{tabular}{cccc}
\hline Layer & \multicolumn{3}{c}{ Calibration } \\
\hline & $\mathrm{k}_{\alpha}$ & $\mathrm{k}^{-1}$ & $\sigma_{\mathrm{k}^{-1}}$ \\
\hline Boundary layer & 0.614 & $7.75 \cdot 10^{-11}$ & $2.26 \cdot 10^{-12}$ \\
Mixed layer & 0.670 & $8.20 \cdot 10^{-11}$ & $1.80 \cdot 10^{-12}$ \\
SAL & 0.679 & $7.80 \cdot 10^{-11}$ & $7.85 \cdot 10^{-13}$ \\
\hline
\end{tabular}

Figure 3 shows the retrieved backscatter coefficient for the flights on 10 July and 11 July based on the calibration constants retrieved during the calibration flight on 26 June. The retrieved backscatter coefficient from the DWL measurements are shown together with the POLIS aerosol lidar measurements in Fig. 4.

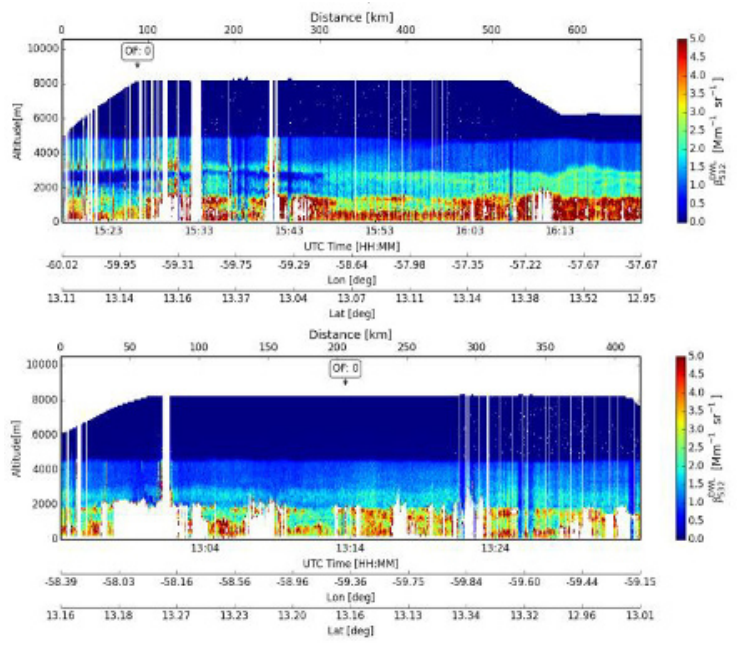

Figure 3. Overview of the retrieved backscatter coefficient for the flights on the 10 July (upper panel) and 11 July (lower panel). The labels "OF" indicate the approximated time of the overflight over POLIS lidar. The white color indicates regions were no atmospheric signal is available (e.g. below clouds, low laser energy).
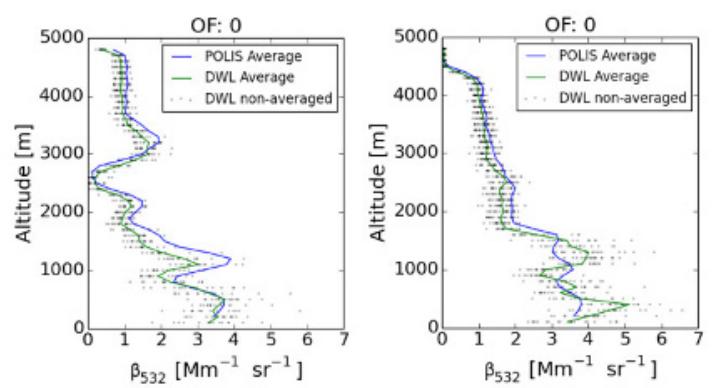

Figure 4. Comparison of the non-averaged (grey dots) and averaged backscatter coefficient profiles (green) corresponding to the retrieved 
data for the flights on the 10 July (left) and 11 July (right), and the averaged profiles measured by POLIS (blue) during the Falcon overflights $(O F)$.

Using the calibration constant corresponding to the SAL, the attenuated backscatter coefficient from the flight on 12 June in the Dakar region was retrieved and compared with the attenuated backscatter coefficient measured by CALIPSO. The results are shown in Fig. 5.
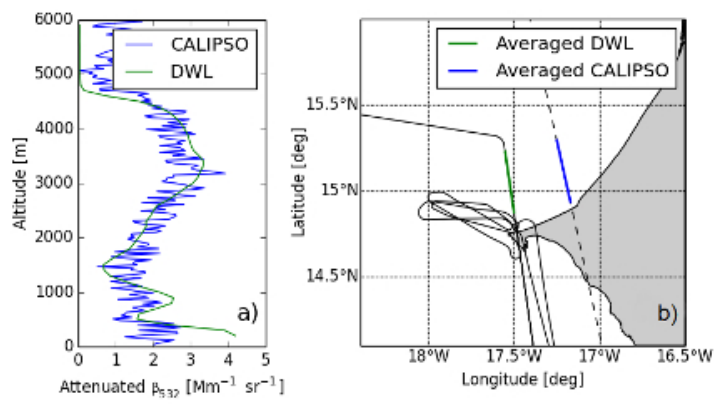

Figure 5. a) Comparison of the averaged attenuated backscatter profiles retrieved from the $D W L$ (green) and the corresponding averaged profile measured by CALIPSO (blue) during its overpass over Dakar region on the 12 June. b) DLR Falcon (black, solid) and CALIPSO (black, dashed) tracks, together with the averaged sections (green for the DWL and blue for CALIPSO).

\section{SUMMARY}

In this study, we showed a method which allows the synchronous retrieval of aerosol backscatter and extinction coefficients from an (airborne) DWL giving detailed insight into aerosol transport but also aerosol properties. The retrieved calibration constants were validated using ground based aerosol lidar and CALIPSO measurements, showing an agreement within $20 \%$.

In further studies, the sea surface return will be tested as monitor of the stability of the retrieved calibration constants.

\section{ACKNOWLEDGEMENT}

This work was funded by the Helmholtz Association under grant number VH-NG-606 (Helmholtz-Hochschul-Nachwuchsforschergruppe AerCARE). The SALTRACE campaign was mainly funded by the Helmholtz Association, DLR, LMU and TROPOS.

\section{REFERENCES}

[1] Menzies, R. T. and Tratt, D. M., 1994: Airborne $\mathrm{CO}_{2}$ coherent lidar for measurements of atmospheric aerosol and cloud backscatter, Applied Optics, 33, 5698-5711.

[2] Bufton, J. L., F. E. Hoge, R. N. Swift, 1983: Airborne measurements of laser backscatter from the ocean surface, Applied Optics, 22, 2603.

[3] Cutten, D. R., J. Rothermel, M. A. Jarzembski, R. M. Hardesty, J. N. Howell, D. M. Tratt, V. Srivastava, 2002: Radiometric calibration of an airborne $\mathrm{CO} 2$ pulsed Doppler lidar with a natural earth surface, Applied Optics, 41, 3530-3537.

[4] O'Connor, E. J., A. J. Illingworth, R. J.Hogan, 2004: A technique for autocalibration of cloud lidar, J. Atmos. Ocean. Tech., 21, 777-786.

[5] Köpp, F., S. Rahm, I. Smalikho, 2004: Characterization of Aircraft Wake Vortices by 2$\mu \mathrm{m}$ Pulsed Doppler Lidar, Journal of Atmospheric and Oceanic Technology, 21, 194-206.

[6] Reitebuch, O., 2012: Wind Lidar for Atmospheric Research, in: Atmospheric Physics, Schumann, U., Springer, Berlin Heidelberg, 487507.

[7] Chouza, F., O. Reitebuch, S. Groß, S. Rahm, V. Freudenthaler, C. Toledano, B. Weinzierl, 2015: Retrieval of aerosol backscatter and extinction from airborne coherent Doppler wind lidar measurements, Atmos. Meas. Tech. Discuss., 8, 1935-1986.

[8] Freudenthaler, V., M. Esselborn, M. Wiegner, B. Heese, M. Tesche, A. Ansmann, D. Müller, D. Althause, M. Wirth, A. Fix, G. Ehret, P. Knippertz, C. Toledano, J. Gasteiger, M. Garhammer, M. Seefeldner, 2009: Depolarization ratio profiing at several wavelengths in pure Saharan dust during SAMUM 2006, Tellus B, 61, 165-179.

[9] Toledano, C., M. Wiegner, S. Groß, V. Freudenthaler, J. Gasteiger, D. Müller, T. Müller, A. Schladitz, B. Weinzierl, B. Torres, N.T. O'Neill, 2011: Optical properties of aerosol mixtures derived from sun-sky radiometry during SAMUM-2, Tellus Series B: Chemical and Physical Meteorology, 63, 635-648. 